account of an indolent, fairly dense and knobby huge tumour, occupying the right side of the neck. Its upper margin reached the inferior edge of the lower jaw and the auricle; the lower extended down to the clavicle anteriorly, and the spina scapulæ posteriorly; the anterior boundary was situated close to the trachea and the larynx, and the posterior in the vicinity of the transverse processes of the cervical vertebræ. The new growth measured vertically $2 \mathbf{I}$ centimetres, and in the antero-posterior diameter 33. The axillary and all other lymphatic glands were normal ; in fact, the examination of all organs failed to detect any deviations from the standard. According to the parents' statement, when the patient was three years of age they had first noticed a globular hard lump of the size of a nut situated on the right side of the neck, midway between the lower jaw and the clavicle. The swelling remained stationary until eight months ago, when it began to steadily and rapidly increase in size, and that notwithstanding a persevering medical treatment. In consideration of the facts, Dr. Mislavsky decided to excise the neoplasm. The operation (under chloroform) lasted about one hour, hæmorrhage being but slight. After the enucleation of the tumour in toto the wound (I 9 centimetres long) was closed with sutures and supplied with drainage. The sutures were removed on the sixth day, when the wound was found healed per primam, except a small area about the lower angle.

The new growth (weighing $\mathrm{I} \frac{3}{4}$ pound) proved to consist of adenoid tissue. In view of its rapid increase, however, the author is inclined to believe that he had to deal not with a simple lymphoma, but with a lympho-sarcoma.

Valerius Idelson.

\title{
EAR, \&c.
}

Szenes (Perth).-An Audible Noise in the Ear. "Internationale Klinische Rundschau," and "Centralblatt fiir Klin. Med.," I89I, p. 87 I.

A GIRL of ten had a "ticking" in one ear, which could be heard at a distance of about five inches, and had a snapping character occurring about 120 to 130 times a minute, not synchronous with the pulse. It continued during sleep. The hearing power was normal, but the drum membrane showed signs of old inflammation. It was supposed to be caused by rhythmical contraction of the tensor tympani or palatal muscles.

Dundas Grant.

Heimann (Warsaw). - Blowes on the Ears. "Arch. of Otol.," I891.

THE author relates a case in which a blow on the ear was followed by death in a week. The patient, who denied previous ear-disease, received a blow on the ear through the irritation caused by his apathetic condition. Acute otitic symptoms followed, and an amount of constitutional disturbance, which led to a diagnostic difficulty in excluding typhoid fever. This was cleared up, and little doubt was then entertained that the ear- 
disease was of old standing, and that septicæmia had set in as its sequence. The autopsy revealed old caries of the petrous and mastoid, thronbo-phlebitis, and septico-pyæmia. This case is of interest in its medico-legal relations. The concealment of the previous existence of eardisease risked the bringing of a charge of manslaughter against the administrator of the blow. In time, possibly, blows on the ears may cease to be administered as an outlet for the irascibility of teachers and others.

Dundas Grant.

Hills, T. Hyde (London). - Cases of Deafness Treated by Injections of Pilocarpin.

"Brit. Med. Journ.," Nov. 14, I891. Cambridge Med. Soc., July Io, I89 I.

THE treatment was carried out daily in two cases for seven weeks, with some slight improvement at first, but ultimately with no results whatever.

Hunter Mackenzie,

Pritchard, Urban (London).-Bony Growths in the Meatus. "Arch. of Otol.," I89I.

THE author classifies them thus:-

Exostoses proper-

I. Multiple ; uniformly smooth and rounded; pale and glistening on the surface ; even denser than ivory in consistence.

2. Irregular in shape ; of pale pinkish hue and dull appearance, with broad bases and of great density.

3. Single polypoid exostoses, consisting of a nucleus, so to speak, of ivory-like consistency, from the surface of which trabeculæ of cancellated bone project into a layer of fibrous tissue, the whole being attached to the outer edge of the osseous meatus by a bony pedicle.

As distinguished from these is the hyperostosis described by Cassells, which is a diffuse enlargement of bony tissue. It is usually a comparatively large but uniform swelling of one side of the osseous wall of the meatus. Its growth may cease at any point, but it may extend till the meatus is completely closed.

Operation is recommended by Mr. Pritchard without delay in the third class of exostoses; in the second, when there is any danger of occlusion of the meatus, and if there is persistent otorrhoa ; in the first, not unless there is any tendency to complete occlusion.

For the third class a dental elevator or stump forceps may be used For the others a trepnine, mounted on an electric or pedal dental engine. $\mathrm{He}$ advises a general anæsthetic in preference to cocaine.

\section{Dundas Grant.}

Kuhn (Strasburg).-Cholesteatoma of the Ear. "Arch. of Otol.," Vol. XX., No. 4 .

TuIs tumour (or tumor) consists of concentric lamellæ, made up of polygonal, flat, non-nucleated epidermoid cells, between which cholesterine crystals lie in greater or less quantities. The pearly gloss is produced, as was already pointed out by Muiller, by the interference of light in the finer concentric layers of the polyhedral cells. According to Virchow, it is at first entirely enclosed in the bone, but frequently it distends the bony cavity by its gradual growth, causes absorption of the bone, which 


\section{Rhinology, and Otology.}

it finally perforates so as to open into the tympanum; the external auditory came on to the surface of the mastoid, and into the middle of posterior cranial fossa. Virchow describes the "capsule" as an exceedingly fine membrane. Mikulicz, Küster, and others, generally accept the neoplastic origin of this growth-possibly an involution of epiblast.

Von Troeltsch explained their existence as products from the surface of the chronically inflamed mucous membrane of the middle ear, which are retained where they are formed, and collect in great massesretention tumours. In favour of Von Troeltsch's view are-(I) the flat arrangement of the cholesteatomatous masses ; (2) their connection with the mucous membranes ; (3) the constant presence of caseous pus in the centre of the growth.

Against this view stands the fact that the cells composing cholesteatomata differ from those of the middle ear, and resemble those of the meatus; also that rare cases of cholesteatoma occur with very acute symptoms, and without any preceding otorrhœa-moreover, the central nucleus of pus is wanting in many cases-and Von Troeltsch does not account for the capsule of connected tissue.

Wendt, though describing a true cholesteatoma (in opposition to Von Troeltsch), thought, with him, that it was commonly a product of desquamative inflammation of the tympanic mucous membrane. Lucae, finding granulations constantly occurring in cases of cholesteatoma, believes that the latter are caused by their shedding their epithelium, the cells of which accumulate in the spaces within the middle car. He has, however, published cases of true primary cholesteatoma.

Habermann, in support of the secondary nature of the growths, brought forward cases in which the epidermic epithelium from the meatus was traced over the edges of a perforation to a cholesteatomata in the middle ear. Bezold, noticing the extreme relative frequency of cholesteatoma in conjunction with tubal catarrh and perforation of Shrapnell's membrane, holds that the catarrh may cause retraction and perforation of Shrapnell's membrane, which may lead to extension of the epidermis, and to the formation of a cholesteatoma in the auditus of the antrum, and the antrum itself.

Kuhn then relates the case of a man who, without previous otorrhoa, noticed attacks of intense tinnitus, especially after violent exercise, with impairment of hearing, staggering, and failure of vision, the dizziness increasing considerably when he pressed his finger against the left mastoid process. He continued in this state for many months, and then, after exposure to cold, suffered from extreme pain in the deeper parts of the ear, followed by purulent discharge from the left auditory canal. He became worse, and on examination was found to have a large fistula in the posterior wall of the meatus, and a very small perforation in the lower anterior segment of the membrane. On operation the mastoid was found to be perforated also, and filled with a typical cholesteatomatous mass, which had eroded its way into the posterior cranial fossa.

In this case it can hardly be supposed that the tumour was other than primary.

Dundas Grant. 
Bezold, Fr. (Munich).-The Treatment of Cholesteatoma of the Middle Ear.

"Arch. of Otol.," Vol. XX., No. 4.

GRANULATIONS, which are present in fifty per cent. of the cases, must be removed (with snare, syringe, sharp spoon, curette, etc.), and carious bone must be scraped. The malleus may have to be removed, and the mastoid to be opened. The cavity is syringed out with a four per cent. boric solution, and boric acid (powder) is insufflated. Bezold, associating cholesteatoma with perforation of Shrapnell's membrane, and attributing the latter to Eustachian catarrh, insists on the therapeutical and prophylactic value of Politzerization and naso-pharyngeal medication.

\section{Dundas Grant.}

Schmiegelow, E.-On Perforations of the Membrane of Shrapnell, with Remarks on the Formation of Cholesteatomata. "Arch. of Otol.," Vol. XX., No. 3 .

$\mathrm{HE}$ considers that these perforations arise from inflammation in the upper cavities of the tympanum (Prussak's space, Kretschmann's space, etc.), originating either in median or external otitis. The reason for their lasting longer than the general tympanic inflammation is that the exudation is pent-up in these partially closed cavities. The inflammation in the largest upper cavity (which he christens the "antrum" of Shrapnell) leads to caries of the head of the malleus and body of the incus and to prolonged suppuration in the "attic" ("cupola" of Hartmann). He declines to accept the explanation that extension from the external ear takes place through a foramen of Rivini, as the existence of such a foramen as a normal occurrence is very unlikely, its presence in the membranes of new-born children not having been observed, and its occurrence in others being probably the result of disease. Cholesteatomata are formed in these spaces owing to the irritation of retained exudation acting on the mucous lining. The lining becomes dermoid like the mucous membrane of the nose in ozæna-layers of pavement epithelium supported on an unmistakable rete Malpighii. In this way layer after layer of cells is thrown off internally, and the cholesteatomatous mass thus formed. He thinks there is no need to ascribe the change in the cells to any migration inwards of the epidermis of the meatus, so exactly do the metaplastic changes in ozæna, and those described by Billroth as taking place in mucous membranes subjected to mechanical insult, correspond with the appearances he has seen in cholesteatoma.

Dundas Grant.

\section{Spratling, L. W.-A Case of Hamatoma Auris without Mental Disease. "Med. Rec.," Nov, 21, I891.}

THE ear suddenly became painful, and in two hours was a hot fluctuating tumour about the size of a hen's egg. On puncture, to cc. of arterial blood was evacuated, and the tumour refilled rapidly. On repetition of the puncture next day it filled again. In nine days the pain was gone, but the tumour was very little reduced in size. It gradually contracted, and in three months' time presented the well-known thickened and puckered appearance. The same thing had happened to the other ear 
two years previously. No history of syphilis, rheumatism, alcoholism, scurvy, or hæmophilia. He was a robust, ruddy, somewhat plethoric sailor.

Dundas Grant

Poli (Geneva).-On Intra-tympanic Operations. " Rev. de Laryngol. d'Otol. et de Rhinol.," Oct. I5, I891.

CONSIDERING chiefly the operation of mobilization of the stapes, and its technique (apparently on the cadaver only), Dr. Poli judges it to be free from danger and worthy of being practised in cases of deafness and tinnitus which do not yield to ordinary means.

In a discussion on the subject, TOTI thought any resulting benefit might be due to persistence of the operative perforation. PoLI said the perforation did not persist. Dr. Cozzolino thought that post-suppurative cases were the most - perhaps the only-favourable cases. He appeared to consider paracusis a contra-indication. CORRODI had seen favourable results in Paris, and thought the operation should be tried when other means failed. MASSINI considered paracusis the principal indication. [MroT's results in a large number of cases would lead us to consider the adhesions following suppuration of the tympanum as the only ones on which the operation might be practised with any great hope of improvement. His account of the antiseptic precautions and method of operation is fully detailed in his monograph on "Mobilization de l'Etrier," Paris, I 884.]

Dundas Grant.

Daudois. - A Case of Cerebral Abscess Evacuated by Trephining. "Rev. Med. de Louvain," I 891 , No. 8.

A Young man of twenty-five had had a discharge from the left middle ear since five years of age. A purulent and foetid discharge had lasted, with intervals, up to three years ago, and hearing was nearly abolished.

On June 13, 1891, after a railway journey and exposure to cold wind, the pains in the ear had reappeared, and were accompanied with intense fever, œdematous swelling of the left auditory meatus and mastoid region. On June i 5 the symptoms were aggravated by the appearance of cerebral phenomena. On June I 8 there was an abundant discharge, followed by subsidence of the alarming phenomena. On June 2 I the central symptoms reappeared, accompanied with paralysis of the right upper limb. Trephining was resorted to. The first operation was performed on the spot recommended by Bergmann, but without restilt. The second was made according to Lucas-Championniere's method; the third immediately behind and below this spot. The cerebral abscess was reached, and about 300 grammes of foetid pus evacuated. Slight improvement followed the operation, but the patient died in coma, forty-eight hours after.

Dr. Daudois adds to the record of this case some considerations upon the utility of trepaning in intra-cranial suppuration following otorrhœa.

Hicguet.

Lichtenberg (Buda-Pesth).-Collapse of the Tympanic Membrane. "Rev. de Laryngol. d'Otol. et de Rhinol.," Oct. 15, I891.

In a case described, the patient had remarkable fluctuations of the hearing power without apparent reason. Three years previously she had 
had an acute otitis, and had been catheterized for two years without any benefit. When Prof. Lichtenberg saw her for the first time the membrane appeared to be entirely wanting. Inflation, which was quite easy, was followed by a clapping sound and great improvement in hearing. On inspection, a bulging of the relaxed membrane nearly filled the inner fourth of the external meatus. The atrophy of the membrane, originally caused by the inflammatory attack, was probably intensified by the continuous use of the Eustachian catheter. [The extremely transient improvement in hearing, following physiological or artificial inflation of the tympanum, is characteristic of relaxed membrane. The most satisfactory method of confirmatory diagnosis is the use of the "pneumatic speculum." Seeing the injurious effect of the continued use of the catheter, or of Politzer's bag in such cases, the routine use of the pneumatic speculum cannot be too strongly insisted on. As regards treatment, we have found considerable benefit follow the use of contractile collodion.]

\section{Dundas Grant.}

\section{Wuirdemann (Milwaukee).-Erysipelas and Acute Inflammation of the Middle Ear. "Med. News," Nov. 21, 189 I.}

THREE cases are described in which acute otitis media supervened in the course of erysipelas. In the first, an apparently simple mucous catarrh of the tympanum recurred in a purulent and violent form after incision of a post-pharyngeal abscess and removal of an hypertrophied pharyngeal tonsil. Erysipelas appeared at the anterior nares, and spread over the face. Paracentesis of the membrane evacuated sanguineous pus, but violent pain continued until the erysipelatous attack completed its course. In the second, facial erysipelas extended through the mouth, pharynx, and Eustachian tube to the middle ear. Perforation took place spontaneously, but relief to pain did not follow. The third, like the other cases, was remarkable for the absence of relief on the evacuation of the intra-tympanic pus. Many "cocci" were found in the pus in the first case.

\section{Dundas Grant.}

Bobone, T. (San Remo). -Menière's Disease consecutive to Infuenza. "Bolletino delle Malat. dell'Orecchio," Nov., I89I.

A GENTLEMAN, aged forty-five, of robust constitution was attacked by influenza in January of the past year, and before the illness was quite over he was seized for the first time with giddiness, loss of consciousness, vomiting, cramps in the throat, etc., lasting a few minutes. In August a similar attack took place, and again in October. Between the attacks he complained of weight in the head, intolerance of light, and slight vertigo. In addition, soon after the first seizure he found himself getting rather deaf. On examination after the attack in October there were found catarrh of the pharynx and Eustachian tubes, no effusion in the tympana, but indrawing and dulness of the membranes. The hearing power was, for the watch, right $\frac{3}{1 \overline{5}} \overline{\bar{v}}$, left $\frac{3}{1 \overline{\bar{\sigma}} \overline{0}}$, and whispered voice was heard at four metres by the right ear, $I^{\circ} 5^{\circ}$ by the left. The $C$ tuning-fork was not heard nearly so long on the left mastoid as on the right. Inflation increased the hearing power for watch tick to $\frac{92}{150}$ on the right side, but only to $\frac{5}{150}$ on the left. There seemed evidence then of a labyrinthine 
lesion-probably hæmorrhage-with middle ear catarrh. Dr. Bobone, wondering at the absence of tinnitus, elicited on closer enquiry that on the occasion of the first attack the patient heard sounds like a chime of bells for a few seconds. The treatment prescribed was Dr. Grazzi's formula :-Quin. valerianat. $4^{\circ} \mathrm{O}$ grammes; extract aconiti $0.80 \mathrm{gr}$. ; ext. cinchon. moll. q.s. ut fiant pill. xxxx. One every six hours; also iodide of potassium, Politzerization, and astringent gargles. The patient soon improved, and had only a slight attack in December. He heard well in the right ear, but the left still remained deaf. Still he was quite free from vertigo. Bobone refers to cases reported by Lannois, of Lyons (French Society of Otology and Laryngology, May Ist, I890), and by Money ("Lancet," May 3, I89o).

Dundas Grant,

Knapp and Bradford (Boston). - Tumour of the Cerebellum, in which Trephining zuas done for the Relief of Pressure. " Med. Rec.,"Sep. 26, 1891 .

Loss of hearing, with some difficulty in swallowing and articulation, came on in a man who had for some time suffered from right occipital headache diplopia, dimness of vision and double optic neuritis, convulsive attacks and later increased headache, nausea, vomiting, blindness, and loss of smell. Mental condition was good. The region over the sylvian fissure was trephined, giving relief to pain. Death occurred in two months, and tubercle was found in the left lobe of the cerebellum. Dundas Grant.

\title{
ASSOCIATION MEETINGS.
}

\section{THE SOCIETY OF LARYNGOLOGY, OTOLOGY, AND RHINOLOGY, OF PARIS.}

\author{
Meeting, June 5, $189 \mathbf{1}$.
}

Eizematous Erythema consequent upon applications of Salol. By Dr. CARTAz.

While even large doses of salol (4-6 grammes) administered internally cause no unpleasant symptoms, eruptions or eczemas may occur in the vicinity of its application to mucous membranes. Morel-Lavallée lately communicated to the Dermatological Society a case of oedematous angina, following upon applications of salol for a suppurative otitis.

The author related two cases. I. An arthritic patient, with chronic pharyn. gitis and obstruction of the right side of the nose, from turbinated hypertrophy, which was removed by the cautery. Insufflations of salol were prescribed twice a day. On the third day the onset of erysipelas was feared by the patient, and Cartaz found an erythema, with swelling and irritation in the nose, and an eruption of vesicles, having all the characters of eczema. Though the irritation was calmed by starch poultices, the next day it had extended, the patient having continued his salol insufflations. When these were discontinued the eczematous attack declined within forty-eight hours.

In a second case, a pseudo-eczematous eruption occurred on the ala of the nose and upper lip, on the second day after using salol insufflations, after cauteri= 